anales de psicología, 2012, vol. $28, \mathrm{n}^{\circ} 2$ (mayo), 338-343 http://dx.doi.org/10.6018/analesps.28.2.148731
(C) Copyright 2012: Servicio de Publicaciones de la Universidad de Murcia. Murcia (España) ISSN edición impresa: 0212-9728. ISSN edición web (http://revistas.um.es/analesps): 1695-2294

\title{
Influence of coping strategies in the specific worries of pregnancy
}

\author{
Francisco J. Carmona-Monge ${ }^{*}$, Dolores Marín-Morales², Cecilia Peñacoba-Puente ${ }^{3}$, \\ Isabel Carretero-Abellán ${ }^{3}$, y María A. Moreno-Moure ${ }^{2}$
}

\author{
${ }_{1}$ Departamento de Enfermería, Universidad Rey Juan Carlos (Madrid, Spain) \\ ${ }_{2}^{2}$ Servicio de Obstetricia, Hospital Universitario de Fuenlabrada (Madrid, Spain) \\ ${ }^{3}$ Departamento de Psicologia, Universidad Rey Juan Carlos (Madrid, Spain)
}

\begin{abstract}
Título: Influencia de las estrategias de afrontamiento en las preocupaciones específicas del embarazo.

Resumen: El objetivo del presente estudio es analizar la influencia de las diferentes estrategias de afrontamiento en las preocupaciones específicas de embarazo. Se evaluó a una muestra formada por 286 gestantes en su primera mitad de embarazo, a las que se administró el Cuestionario de Afrontamiento al Estrés, y la Cambridge Worry Scale. Además se recogieron variables sociodemográficas (edad, nivel de estudios, embarazos previos, situación laboral y planificación de embarazo). Se observó una relación significativa entre las preocupaciones del embarazo y las estrategias de autofocalización negativa, expresión emocional abierta y evitación. El análisis de regresión evidenció una influencia significativa de la estrategia de autofocalización negativa y la paridad sobre las preocupaciones del embarazo. Estos resultados sugieren que un afrontamiento caracterizado por una percepción de incapacidad para manejar las situaciones, tiene un efecto negativo en la condición psicológica de la gestante. La experiencia de un parto previo podría atenuar este efecto. De este modo, se destaca la importancia de la atención psicológica en la embarazada, con la finalidad de que, desde el inicio de la gestación, y especialmente en primíparas, se desarrollen recursos para adaptarse a la nueva situación y mejorar la salud de la mujer.
\end{abstract}

Palabras clave: embarazo; estrés psicológico; estrategias de afrontamiento; preocupación.

Pregnancy is considered a vital event that may create a threatening situation. In the event of a response to stress, the use of different and more or less effective coping strategies will have some psychological and physiological consequences on the person.

Regarding the physiology, problem solving and positive reappraisal coping strategies are associated with better health while confrontation, avoidance and escape strategies have a negative effect (Orejudo Hernández \& Froján Parga, 2005; Penley, Tomaka, \& Wiebe, 2002).

Regarding psychological health, different studies have revealed that problem solving coping, social support seeking, actively looking for a distraction and seeking out information and participation in rituals, are associated with better psychological adjustment whilst escape/avoidance, wishful thinking, reflection, desperation and abandonment, social isolation and intense emotional expression and anger towards the person responsible could generate psychological symptoms, mainly anxiety and depression (Campos, Iraurgui, Páez, \& Velasco, 2004; Compas, Connor-Smith, Saltzman, Thomsen, \& Wadsworth, 2001; Penley, Tomaka, \& Wiebe, 2002; Skinner, Edge, Altman, \& Sherwood, 2003).

* Dirección para correspondencia [Correspondence address]: Francisco Javier Carmona Monge. C/República Checa, 9, $3^{\circ}$ B. 28032 , Madrid (Spain). E-mail: dmarin.hflr@salud.madrid.org
Abstract: The aim of this study is to analyse the influence of the different coping strategies on specific pregnancy-related worries. We assessed a sample comprised of 285 pregnant women during the first half of pregnancy who underwent the Coping Strategies Questionnaire, and the Cambridge Worry Scale. In addition, sociodemographic variables were collected (age, education, prior pregnancies, occupational situation and pregnancy planning). We observed a significant relationship between pregnancyrelated worries and negative auto-focused coping, overt emotional expression coping and avoidance coping. Regression analysis revealed a significant influence of negative auto-focused coping and number of children on pregnancy-related worries. These results suggest that coping characterised by perception of incapacity to handle situations has a negative effect on the pregnant woman's psychological condition. The experience of a prior birth could reduce this effect. Therefore, we highlight the importance of psychological care for the pregnant woman with the purpose of, from the onset of gestation and especially in women pregnant for the first time, developing resources to adapt to the new situation and improve women's health.

Key words: pregnancy; coping strategies; psychological stress; worry.

There are different investigations focused on coping strategies used during pregnancy, and the possible consequences for well being and symptoms perceived by the pregnant woman. Therefore, it has been revealed that one type of spiritual coping and acceptance of the situation is more frequently used in pregnant women while the least frequently used strategy is avoidance which is associated with depression, anxiety and distress specific to pregnancy (Hamilton \& Lobel, 2008).

It has also been found that those strategies focused on emotion are negatively related to specific pregnancy-related complaints and perceived stress (Huizink, de Medina, Mulder, Visser, \& Buitelaar, 2002). Some studies have even revealed more long-term effects; it has been found that coping while feeling depressed increases the risk of post-partum depression (Demyttenaere, Lenaerts, Nijs, \& Van Assche, 1995).

Risky pregnancy as a pathological condition that requires special follow up has meant the development of several investigations to assess the degree of stress and how to handle this. It has been found that in this group of patients, stress levels are moderately high; the strategy of positive reappraisal is related to less perception of risk and distress by the pregnant woman (Yali \& Lobel, 1999). In the case of hypertension during pregnancy, women tend to use social support strategies to a greater extent compared to positive reappraisal strategies (Bjelica \& Kapor-Stanulovic, 2004). Regarding the use of antenatal diagnosis techniques such as amniocen- 
tesis, cognitive coping and avoidance coping are associated with more anxiety in pregnant women (López-Valverde, Fernández, Páez, Ortiz, \& Alvarado, 2001).

The experience of spontaneous miscarriage may also be a highly threatening situation that has consequences for the woman's psychological health; aspects such as self esteem and feelings of personal responsibility, associated with more symptoms of anxiety and depression following the loss, are especially important (Nikcevic, Kuczmierczyk, \& Nicolaides, 2007). In addition, for subsequent pregnancies, woman who were depressed when trying to cope following a miscarriage or anxiety during mourning present higher levels of anxiety and depression (Bergner, Beyer, Klapp, \& Rauchfuss, 2008).

Regarding infertility and the use of assisted reproduction techniques, those women who use overt emotional expression as a coping strategy, are less likely to become pregnant following in vitro fertilisation (IVF) (Panagopoulou, Vedhara, Gaintarzti, \& Tarlatzis, 2006).

Worry is a cognitive process which entails images and thoughts (loaded with negative feelings and relatively uncontrollable), which, if they occur intensely and persistently, may lead to a psychological condition and turn into a pathological process (Dugas, Gagnon, Ladouceur, \& Freeston, 1998), and they frequently occur during anxiety disorders (Purdon \& Harrington, 2006). Although worry and anxiety are two highly related concepts, they are clearly differentiated (Davey, Hampton, Farrell, \& Davidson, 1992). Anxiety is defined as a physiological and psychological state marked by cognitive, somatic, emotional and behavioural components while worry refers to the cognitive component of anxiety and may even be the cause of this (Purdon \& Harrington, 2006).

Several investigations have revealed that during pregnancy, there are a series of specific pregnancy-related worries (Affonso, Liu-Chiang, \& Mayberry, 1999). Worry focused on the fetus' health has also highlighted in different studies, situational factors such as how the use of fertility techniques seems to increase the existence of worries (Hjelmstedt, Widstrom, Wramsby, Matthiesen, \& Collins, 2003).

An association between pregnancy-related worries and anxiety has also been found (Green, Kafetsios, Statham, \& Snowdon, 2003), and has even been related to an increased risk of obstetric complications such as premature birth (Orr, Reiter, Blazer, \& James, 2007).

Bearing in mind therefore the evidence set out in aspects of coping and worries, we considered to what extent less effective strategies to handle different situations could be related to these psychological consequences; specifically, those thoughts most characteristic of the gestation process. Therefore, the aim of this study is to analyse the influence of the different coping strategies on specific pregnancy-related worries.

\section{Method}

\section{Design}

To prepare the study an ex post facto, retrospective study was designed and subjects were voluntarily assigned to the study sample.

\section{Participants}

A total of 406 questionnaires were sent out; the response rate was $69.95 \%$. The sample was therefore finally comprised of 285 women with an average age of 31.05 (SD $=$ 4.94) during the first half of pregnancy $(M=14.41, S D=$ 2.08 weeks). As for educational level of the sample, $27.4 \%$ had primary studies, $45.3 \%$ secondary studies and $27 \%$ higher education, and $64.9 \%$ of the women were working when the study was carried out. A high percentage $(82.8 \%)$ had planned the pregnancy and approximately half had already had at least one child (49.1\% had several children). All of them belonged to Fuenlabrada Hospital located within Area 9, of the Community of Madrid. Inclusion criteria were women aged over 18 who understood and spoke fluent Spanish; clinical criteria were no psychiatric pathology diagnosed prior to the study or maternal or fetal pathology found before sending the questionnaires which could compromise the clinical course of the pregnancy.

Women who did not completely fill in the questionnaires were subsequently excluded from the study.

\section{Variables and instruments}

Specific worries about pregnancy were measured with the Cambridge Worry Scale (CWS) (Statham, Green, \& Kafetsios, 1997). This is a structured self assessment questionnaire which reflects characteristic worries of the pregnant woman, comprised of 16 items, with five alternative answers in a Likert type format ranging from 0 (not a worry) to 5 (extremely worrying). The factorial analysis revealed a four factor structure corresponding to the characteristic worries of the pregnant woman: socio-sanitary, socio-economic, their own health and the health of people close to them, and interpersonal relationships (Green et al., 2003). Different studies have revealed a high level of reliability and validity of the scale (Ohman, Grunewald, \& Waldenstrom, 2003). The Spanish version of the questionnaire was prepared in accordance with the recommendations for test adaptations (Hambleton \& Patsula, 1999) and four translators with advanced level of Spanish and English and familiarity with both cultures, translated the scale. The reliability of the scale in this study was considerably acceptable with a Cronbach alpha of .86; the reliability of the different factors ranged from between .81 (interpersonal relationships) to .70 (sociohealth aspects).

Coping styles were measured by means of the structured self assessment known as a Coping Strategies Questionnaire 
(Cuestionario de Afrontamiento del Estrés [CAE]) (Sandín \& Chorot, 2003). The Coping Strategies Questionnaire was used to measure seven basic coping styles which consist of: problem solving coping (setting out solutions to try and resolve the threatening condition), negative auto-focused coping (this refers to the negative nature of some strategies such as self guilt, denial or resignation), positive reappraisal (referring to looking for the positive aspects of the situation), overt emotional expression (referring to emotional discharge), avoidance coping (referring to those strategies aimed at forgetting about the situation), social support seeking (resorting to patients and people close to them to resolve the problem) and religious coping (in agreement with spiritual help, trust in a higher being). This questionnaire has 42 items, with a Likert-type answer scale of 4 points, ranging from 0 (never) to 4 (almost always). The minimum score on each subscale is 0 , while the maximum score is 24 . Cronbach alpha reliability coefficients for the seven subscales for this investigation varied between .64 (positive reappraisal) and .92 (social support seeking).

The remaining variables, referring to the sociodemographic data age, number of children, education, occupation and pregnancy planning were collected by means of a questionnaire prepared by the research team. The remaining data, essential to determine exclusion/inclusion criteria, were assessed through the clinical record.

\section{Procedure}

Data was captured by telephone after verifying the result of the first trimester ultrasound in the computerised clinical history. Once the patient was informed and after having agreed to participate, the documents to fill in were sent out by mail which, once filled in, were returned by mail to the Department of Obstetrics.

The study was approved by the ethics committee attached to the hospital. Pregnant women provided signed informed consent once they were included voluntarily in the study.

\section{Data analysis}

For comparisons between groups in the Cambridge Worry Scale and Coping Strategies Questionnaire scores regarding demographic variables, Student's t-test and Snedecor's F test were used. Pearson's correlation coefficient was used to analyze the relationships between the variables at issue.

A regression model was designed for predictive purposes to assess the influence of the different coping strategies and sociodemographic variables on specific pregnancy-related worries. We followed the parsimony principle to determine the simplest model. Therefore, a maximum model was adjusted by subsequently eliminating the variable with the least partial F which did not attain statistical significance $(p<.05)$. The process was repeated consecutively until no more varia- bles could be eliminated (Abraira \& Pérez, 1996; Kleinbaum \& Kleinbaum, 2007). In addition, relevant regression diagnoses were performed according to Fox (Fox, 1991), to verify the model assumptions (linearity, homoscedasticity bearing in mind the graph of residuals, independence by means of the Durbin-Watson statistic, normal distribution of the residuals with the Kolmorogov-Smirnov test). A study of the influential values was performed by means of Cook's distance according to the criteria of Cook and Weisberg (Cook \& Weisberg, 1982). No abnormalities were found.

All statistical analyses were performed at a 95\% confidence interval and a $p$ value under .05 was considered statistically significant. The software used during the analysis was the SPSS (version 16.0).

\section{Results}

The mean total scores on the worry scale was 1.91 . If we analyse the kind of worry in the sample from this study, the most notable worries were those referring to the baby's health $(M=4.09, S D=1.03)$, the threat of spontaneous miscarriage $(M=3.60, S D=1.49)$, and the health of people close to the mother $(M=2.89, S D=1.68)$. For the comparison of means analysis for sociodemographic data we found a statistically significant difference in worries between women with no children and mothers who had had at least one child $\left(t(280)=2.862, p=.002, \eta^{2}=.034\right.$, see Table 1 for means).

The coping strategies most frequently used by pregnant women corresponded to problem solving coping $(M=$ 14.91, $S D=4.06)$, positive reappraisal $(M=14.00, S D=$ $3.33)$ and social support seeking $(M=14.19$, $S D=5.48)$, while those less frequently used were religious coping $(M=$ 3.21, $S D=4.50)$, overt emotional expression $(M=7.37, S D$ $=3.31)$ and negative auto-focused coping $(M=7.21, S D=$ 3.25). Regarding sociodemographic variables, we found a negative relationship between social support seeking and age $r=-.128, p=.038$. We also found statistically significant differences in scores for positive reappraisal and planning pregnancy $\left(t(278)=-2.098, p=.037, \eta^{2}=.016\right)$, religious coping and current occupational situation $(t(278)=2.152, p$ $\left.=.033, \eta^{2}=.019\right)$, and avoidance coping and having several children $\left(t(277)=2.091, p=.037, \eta^{2}=.016\right)($ See Table 1$)$.

The correlation analysis revealed a positive relationship between worries and negative auto-focused coping $(r=.248$, $p=.001)$, overt emotional expression $(r=.166, p=.021)$ and avoidance coping $(r=.152, p=.039)$ (Table 2).

Finally, we prepared a regression analysis, starting with a maximum model introducing sociodemographic variables and coping strategies leading to a final model $\left(R^{2}=.106, p<\right.$ $.001)$, with a statistically significant effect of negative autofocused coping and prior births on pregnancy worries (Table 3). 
Table 1. Characteristics of the sample and average scores among the different groups.

\begin{tabular}{|c|c|c|c|c|c|c|c|c|c|}
\hline & & Worries & $\begin{array}{l}\text { Problem } \\
\text { solving }\end{array}$ & $\begin{array}{l}\text { Negative } \\
\text { auto- } \\
\text { focused }\end{array}$ & $\begin{array}{l}\text { Positive } \\
\text { reappraisal }\end{array}$ & $\begin{array}{l}\text { Overt } \\
\text { emotional } \\
\text { expression }\end{array}$ & Avoidance & $\begin{array}{l}\text { Social support } \\
\text { seeking }\end{array}$ & $\begin{array}{l}\text { Religious } \\
\text { coping }\end{array}$ \\
\hline & $\mathrm{n} \%$ & $\mathrm{M}(\mathrm{SD})$ & & & & & & & \\
\hline \multicolumn{10}{|l|}{ Number of children } \\
\hline First pregnancy & 50.71 & $2.07(0.88)$ & $15.32(4.16)$ & $7.19(3.51)$ & $14.01(3.33)$ & $7.30(3.50)$ & $9.60(3.99)$ & $14.27(5.82)$ & $3.40(4.64)$ \\
\hline Multiple pregnancies & 49.29 & $1.75(0.79)$ & $14.50(3.95)$ & $7.26(2.94)$ & $13.89(3.23)$ & $7.50(3.12)$ & $8.67(3.38)$ & $14.08(5.14)$ & $3.01(4.39)$ \\
\hline$p$ & & .002 & .095 & .851 & .767 & .614 & .037 & .768 & .467 \\
\hline \multicolumn{10}{|l|}{ Education } \\
\hline Primary & 27.56 & $1.87(0.92)$ & $14.32(3.99)$ & $7.97(3.81)$ & $13.69(3.38)$ & $7.53(3.98)$ & $9.26(4.04)$ & $13.62(5.68)$ & 3.81 (4.77) \\
\hline Secondary & 45.23 & $1.98(0.81)$ & $14.79(4.12)$ & $6.86(3.15)$ & $13.92(3.56)$ & $7.51(3.20)$ & $9.11(3.71)$ & $14.62(5.40)$ & $3.01(4.52)$ \\
\hline Higher education & 27.21 & $1.84(0.88)$ & $15.79(3.93)$ & $7.05(2.63)$ & $14.52(2.82)$ & $7.04(2.72)$ & $9.19(3.30)$ & $14.19(5.36)$ & $2.97(4.22)$ \\
\hline$p$ & & .425 & .486 & .070 & .051 & .561 & .963 & .442 & .402 \\
\hline \multicolumn{10}{|l|}{ Pregnancy planning } \\
\hline No & 17.25 & $2.00(0.89)$ & $14.04(4.69)$ & $7.18(3.09)$ & $13.10(3.33)$ & $7.92(3.70)$ & $8.61(3.99)$ & $14.10(6.16)$ & $3.14(4.69)$ \\
\hline Yes & 82.75 & $1.89(0.85)$ & $15.10(3.90)$ & $7.21(3.30)$ & $14.19(3.31)$ & $7.26(3.22)$ & $9.26(3.65)$ & $14.21(5.34)$ & $3.23(4.47)$ \\
\hline$p$ & & .425 & .097 & .957 & .037 & .206 & .269 & .899 & .904 \\
\hline \multicolumn{10}{|l|}{ Prior miscarriages } \\
\hline No & 72.18 & $1.90(0.88)$ & $15.06(3.97)$ & $7.18(3.38)$ & $13.79(3.37)$ & $7.21(3.24)$ & $9.11(3.70)$ & $14.28(5.37)$ & $3.01(4.45)$ \\
\hline Yes & 27.82 & $1.95(0.79)$ & $14.53(4.30)$ & $7.27(2.93)$ & $14.56(3.18)$ & 7.79 (3.48) & $9.24(3.77)$ & $13.97(5.78)$ & $3.74(4.63)$ \\
\hline$p$ & & .645 & .330 & .841 & .086 & .187 & .785 & .680 & .222 \\
\hline \multicolumn{10}{|l|}{ Works currently } \\
\hline No & 34.51 & $1.89(0.91)$ & $14.75(4.23)$ & $7.47(3.50)$ & $13.87(3.41)$ & $7.42(3.45)$ & $8.98(3.60)$ & $14.64(5.31)$ & $4.07(5.29)$ \\
\hline Yes & 65.49 & $1.92(0.84)$ & $15.00(3.99)$ & $7.07(3.13)$ & $14.05(3.29)$ & $7.33(3.25)$ & $9.23(3.79)$ & $13.94(5.58)$ & $2.65(3.99)$ \\
\hline$p$ & & .794 & .627 & .333 & .678 & .839 & .596 & .315 & .033 \\
\hline
\end{tabular}

Table 2. Correlations between the total score on the CWS and the scores on the dimensions of the Coping Strategies Questionnaire.

\begin{tabular}{|c|c|c|c|c|c|c|c|c|}
\hline & & 1 & 2 & 3 & 4 & 5 & 6 & 7 \\
\hline 1 & Pregnancy-related worries & - & & & & & & \\
\hline 2 & Problem solving coping & -.008 & - & & & & & \\
\hline 3 & Negative auto-focused coping & $.279 * *$ & $-.185^{* *}$ & - & & & & \\
\hline 4 & Positive reappraisal & .024 & $.392 * *$ & .048 & - & & & \\
\hline 5 & Overt emotional expression & $.172 * *$ & -.08 & $.439 * *$ & .017 & - & & \\
\hline 6 & Avoidance coping & $.134 *$ & -.009 & $.405^{* *}$ & $.266^{* *}$ & $.237 * *$ & - & \\
\hline 7 & Social support seeking & .004 & $.366^{* *}$ & .051 & $.136^{*}$ & $.248^{* *}$ & $.178^{* *}$ & - \\
\hline 8 & Religious coping & .077 & $.161 * *$ & $.143^{*}$ & $.130 *$ & $.179 * *$ & .100 & $.159 * *$ \\
\hline
\end{tabular}

Note. ${ }^{*} p<.05 ; * * p<.01$

Table 1. Regression analysis to predict pregnancy worries considering coping strategies and sociodemographic variables.

\begin{tabular}{|c|c|c|c|c|}
\hline & \multirow{2}{*}{ Beta } & \multirow{2}{*}{$p$} & \multicolumn{2}{|c|}{ IC 95\% } \\
\hline & & & IL & SL \\
\hline Negative auto-focused coping & 0.271 & $<.001$ & 0.042 & 0.101 \\
\hline Number of children & -0.183 & .002 & -0.503 & -0.12 \\
\hline
\end{tabular}

Note. CI, confidence interval; IL, inferior level; SL, superior level

\section{Discussion}

In accordance with the results obtained we need to mention different aspects regarding coping strategies used by pregnant women, specific worries over pregnancy in the study sample and how the use of certain coping strategies can have an effect on the onset of pregnancy-related worries.

By analysing coping strategies, those most frequently used were problem solving coping, social support seeking and positive reappraisal which is similar to studies with other Spanish populations (Sandín \& Chorot, 2003). In accordance with prior investigations, these strategies have proven to be beneficial to reduce the impact of the stressful event as set out above while social support has proven to be broadly beneficial in reducing the possible adverse consequences of a stressful event (Campos et al., 2004; Penley et al., 2002). Specifically, it has been seen that during gestation, problem solving coping could be beneficial as this is related to less complaints in populations of pregnant women (Huizink, de Medina, Mulder, Visser, \& Buitelaar, 2002). Another point to set out would be that during pregnancy, as an aspect which cannot be altered or removed, positive reappraisal coping, turns into an ideal strategy to reduce stress when positively analysing the situation and thereby favouring adaptation. However, according to our results, these strategies do not reduce worries which suggests that they are not always successful or they are less effective in reducing anxiety 
and reflection which strengthens other aspects of the adjustment such as positive affectivity or social integration (Campos et al., 2004).

The negative relationship found in the results between age and social support seeking could be interpreted that as women age, they learn to use internal resources to a greater extent to handle stressful situations whilst when they are younger, they resort more to people close to them to tackle threatening situations. The results are in accordance with those obtained in studies with another type of population (Blanchard-Fields, 2009).

Another aspect to also consider is the statistically significant difference in scores for religious coping depending on occupational situation in addition to differences over avoidance coping and having several children. The fact that women in an active occupational situation score significantly less in religion could be because of the fact that they are more noted for their own, autonomous and internal effort to set their aims, whilst women with a tendency to score more on religious coping see the performance of an individual work as a priority which is inferior to the need for support from associates and external aspects (aspects characteristic of a tendency for spiritual coping) (Skinner, Edge, Altman, \& Sherwood, 2003).

The difference established by having several children on avoidance coping leads to reflection about the idea that maternity is a process during which the woman learns to rule out passive and not very useful strategies to adapt to situations, thereby preparing the woman for more effective coping with subsequent stressful events.

Regarding worries, this study stresses a very high score for worries related to the baby's health which coincides with other studies (Ohman et al., 2003). The tendency for pregnant women to worry about fetal health would be, first, because the mother's ultimate aim is to have a healthy child which enables them to form a family which lasts over time and which increases their well being, and second, the medical monitoring performed during the clinical course of the gestation is constantly focused on assessing fetal well-being indicators, in continually perceiving the interest of professionals to search and assess possible fetal abnormalities; an actual number of these really occur. However, the possibility of spontaneous miscarriage and health of people close to the mother, with an equally high score, differs from other investigations which put more stress on giving birth, which is perhaps influenced by the resources surrounding the birth in the study population. In Madrid, the woman attends a hospital; the options given in other countries, such as birth houses or home births, are rare. There are therefore suitable resources given both possible obstetric and neonatal complications and, regarding intra birth handling, pain control may easily be resolved with epidural analgesia. The baby's health or the health of those close to the mother could be seen as a less controllable situation which would increase the risk of generating the cognitive process characteristic of worry.
The significant difference in CWS scores found between women with no children and several children reveals the probable weight played by experience which would reduce the formation of dysfunctional ideas on the clinical course of gestation. This means that for a woman giving birth for the first time, pregnancy, as an unknown, may increase worrying thoughts while women with several children have the prior experience of pregnancy as something which attenuates psychological unease. Women who are experiencing their first pregnancy could therefore need a more rigorous assessment regarding their worries and professional support to reduce the psychological discomfort caused.

The positive relationship between negative auto-focused coping, avoidance coping, and overt emotional expression and the total worries score, helps to confirm the findings from other investigations on the relationship between the type of coping and psychological consequences. Therefore, it has been seen that overt emotional expression is not a very effective strategy and has a negative relationship on affectivity, social adjustment and disease (Grippo \& Johnson, 2009; Penley et al., 2002).

Regarding negative auto-focused coping, this is a strategy which may end up producing negative affectivity and hinder assimilation of a fact (Penley et al., 2002). A high self observance and internal attribution of stressful facts is dysfunctional for affective regulation (Campos et al., 2004), and may increase worries (Robichaud, Dugas, \& Conway, 2003). Avoidance may also be associated with anxiety and cause psychological unease (Penley et al., 2002), showing that in studies with pregnant women, this causes more distress for the pregnant woman (Yali \& Lobel, 1999).

Nonetheless, in accordance with the regression analysis, the fundamental weight of the influence of the variables studied on pregnancy worries, corresponds to negative autofocused coping and the factor of prior experience with pregnancy and childbirth in spite of having a discreet explanatory capacity, as it only explains $10 \%$ of the variance. Women giving birth for the first time and with ideas focused on self guilt, perception of incapacity, defencelessness and resignation would have a higher risk of experiencing worries related to pregnancy.

Therefore, we have to stress the damaging effect of negative auto-focused coping, a passive strategy during which the person generates ideas of incapacity to face up to situations to the extent that they could lead to an increase in specific worries about pregnancy.

Given the results obtained, first we should consider the limitations of this research. On the one hand, this is a transversal study; in the future it should be possible to perform a longitudinal study by assessing the independent variables at a moment in time prior to the pregnancy and subsequently analyse specific pregnancy worries with the purpose of assessing a causal relationship. It is feasible that people with more anxiety simultaneously reflect more about themselves and are more worried about the pregnancy; the level of negative affectivity is the causal variable. Only longitudinal stud- 
ies can unravel the actual relationships. Another of the aspects to consider is the generalisation of results to other populations, a fact which could be seen as less important if we consider authors who defend the relative stability of different coping styles, in addition to the universal nature of worry.

\section{Conclusions}

As a conclusion, those pregnant women who may have varying degrees of difficulty in coping with their pregnancy-a

\section{References}

Abraira, V., \& Pérez, A. (1996). Métodos multivariantes en bioestadística. Madrid: Centro de Estudios Ramón Areces.

Affonso, D. D., Liu-Chiang, C. Y., \& Mayberry, L. J. (1999). Worry: Conceptual dimensions and relevance to childbearing women. Health Care for Women International, 20(3), 227-236.

Bergner, A., Beyer, R., Klapp, B. F., \& Rauchfuss, M. (2008). Pregnancy after early pregnancy loss: A prospective study of anxiety, depressive symptomatology and coping. Journal of Psychosomatic Obstetrics and Gynaecology, 29(2), 105-113.

Bjelica, A., \& Kapor-Stanulovic, N. (2004). Pregnancy as a psychological event [Trudnoca kao psiholoski dogadaj]. Medicinski Pregled, 57(3-4), 144-148.

Blanchard-Fields, F. (2009). Flexible and adaptive socio-emotional problem solving in adult development and aging. Restorative Neurology and Neuroscience, 27(5), 539-550.

Campos, M., Iraurgui, J., Páez, D., \& Velasco, C. (2004). Afrontamiento y regulación emocional de hechos estresantes. Un meta-análisis de 13 estudios. Boletin De Psicología, 82, 25-44.

Compas, B. E., Connor-Smith, J. K., Saltzman, H., Thomsen, A. H., \& Wadsworth, M. E. (2001). Coping with stress during childhood and adolescence: Problems, progress, and potential in theory and research. Psychological Bulletin, 127(1), 87-127.

Cook, R.D., \& Weisberg, S. (1982). Residuals and influence in regression. New York: Chapman and Hall.

Davey, G. C., Hampton, J., Farrell, J., \& Davidson, S. (1992). Some characteristics of worrying: Evidence for worrying and anxiety as separate constructs. Personality and Individual Differences, 13(2), 133-147.

Demyttenaere, K., Lenaerts, H., Nijs, P., \& Van Assche, F. A. (1995). Individual coping style and psychological attitudes during pregnancy and predict depression levels during pregnancy and during postpartum. Acta Psychiatrica Scandinavica, 91(2), 95-102.

Dugas, M. J., Gagnon, F., Ladouceur, R., \& Freeston, M. H. (1998). Generalized anxiety disorder: A preliminary test of a conceptual model. Behaviour Research and Therapy, 36(2), 215-226.

Fox, J. (1991). Regression diagnostics. Newbury Park, CA: SAGE Publications.

Green, J. M., Kafetsios, K., Statham, H. E., \& Snowdon, C. M. (2003). Factor structure, validity and reliability of the cambridge worry scale in a pregnant population. Journal of Health Psychology, 8(6), 753-764.

Grippo, A. J., \& Johnson, A. K. (2009). Stress, depression and cardiovascular dysregulation: A review of neurobiological mechanisms and the integration of research from preclinical disease models. Stress, 12(1), 1-21.

Hambleton, R. K., \& Patsula, L. (1999). Increasing the validity of adapted tests: Myths to be avoided and guidelines for improving test adaptation practices. Journal of Applied Testing Technology, 1(1), 1-16.

Hamilton, J., \& Lobel M. (2008). Types, patterns, and predictors of coping with stress during pregnancy: Examination of the revised prenatal coping inventory in a diverse sample. Journal of Psychosomatic Obstetrics and Gynaecology, 29(2), 97-104.

Hjelmstedt, A., Widstrom, A. M., Wramsby, H., Matthiesen, A. S., \& Collins, A. (2003). Personality factors and emotional responses to preg- process which also entails preparing for future maternity-living with the usual somatic symptoms of pregnancy, in addition to pregnancy-related emotional situations, could benefit from psychological care, whose purpose is to develop strategies which favour coping and reduce the risk of generating specific pregnancy-related worries.

Note: El presente estudio ha sido financiado por el Fondo de Investigaciones Sanitarias, proyecto número PI070571, del Instituto Carlos III de Madrid (Spain).

nancy among IVF couples in early pregnancy: A comparative study. Acta Obstetricia Et Gynecologica Scandinavica, 82(2), 152-161.

Huizink, A. C., de Medina, P. G., Mulder, E. J., Visser, G. H., \& Buitelaar, J. K. (2002). Coping in normal pregnancy. Annals of Behavioral Medicine: A Publication of the Society of Behavioral Medicine, 24(2), 132-140.

Kleinbaum, D. G., \& Kleinbaum, D. G. (2007). Applied regression analysis and other multivariable methods (4th ed.). Australia, Belmont, CA: Brooks/Cole.

López-Valverde, M., Fernández, I., Páez, D., Ortiz, A., \& Alvarado, R. (2001). [Anxiety before pregnancy and confrontation and avoidance coping in women to the test of amniocentesis]. Boletin de Psicología, 70, 65-78.

Nikcevic, A. V., Kuczmierczyk, A. R., \& Nicolaides, K. H. (2007). The influence of medical and psychological interventions on women's distress after miscarriage. Journal of Psychosomatic Research, 63(3), 283-290.

Ohman, S. G., Grunewald, C., \& Waldenstrom, U. (2003). Women's worries during pregnancy: Testing the cambridge worry scale on 200 Swedish women. Scandinavian Journal of Caring Sciences, 17(2), 148-152.

Orejudo Hernández, S., \& Froján Parga, M. X. (2005). Síntomas somáticos: Predicción diferencial a través de variables psicológicas sociodemográficas, estilos de vida y enfermedades. Anales de Psicología, 21(2), 276-285.

Orr, S. T., Reiter, J. P., Blazer, D. G., \& James, S. A. (2007). Maternal prenatal pregnancy-related anxiety and spontaneous preterm birth in Baltimore, Maryland. Psychosomatic Medicine, 69(6), 566-570.

Panagopoulou, E., Vedhara, K., Gaintarzti, C., \& Tarlatzis, B. (2006). Emotionally expressive coping reduces pregnancy rates in patients undergoing in vitro fertilization. Fertility and Sterility, 86(3), 672-677.

Penley, J. A., Tomaka, J., \& Wiebe, J. S. (2002). The association of coping to physical and psychological health outcomes: A meta-analytic review. Journal of Behavioral Medicine, 25(6), 551-603.

Purdon, C., \& Harrington, J. (2006). Worry in psychological disorders. In G. C. Davey, \& A. Wells (Eds.), Worry and psychological disorders: Theory, assessment and treatment (1st ed., pp. 41-50). Chichester: John Wiley \& Sons Ltd.

Robichaud, M., Dugas, M. J., \& Conway, M. (2003). Gender differences in worry and associated cognitive-behavioral variables. Journal of Anxiety Disorders, 17(5), 501-516.

Sandín, B., \& Chorot, P. (2003). Cuestionario de afrontamiento del estrés (CAE): Desarrollo y validación preliminar. Revista De Psicopatología y Psicología Clínica, 8(1), 39-54.

Skinner, E. A., Edge, K., Altman, J., \& Sherwood, H. (2003). Searching for the structure of coping: A review and critique of category systems for classifying ways of coping. Psychological Bulletin, 129(2), 216-269.

Statham, H., Green, J. M., \& Kafetsios, K. (1997). Who worries that something might be wrong with the baby? A prospective study of 1072 pregnant women. Birth, 24(4), 223-233.

Yali, A. M., \& Lobel, M. (1999). Coping and distress in pregnancy: An investigation of medically high risk women. Journal of Psychosomatic Obstetrics and Gynaecology, 20(1), 39-52.

(Article received: 27-09-2010, reviewed: 31-07-2011, accepted: 28-08-2011) 